\title{
DURABILITY OF FLEXIBLE PAVEMENTS: A CASE STUDY OF SOUTH- EASTERN NIGERIA
}

\author{
I. N. Obeta ${ }^{1}$ and J. E. Njoku ${ }^{2}$ \\ 1,2 DePartment of Civil EnGineEring, University of Nigeria, NSUKKA, ENUGU STATE NIGERIA

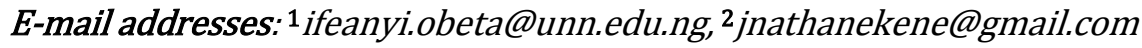

\begin{abstract}
This study presents the evaluation of flexible pavements in the south-eastern Nigeria in terms of their durability in years, ranking, predominant factors affecting pavement durability and the estimate of durability. In this regard, two separate questionnaires of different contents focusing on the nature of the pavements and their constituent materials, their design and construction process, the disposition of the persons involved in their construction and the interaction of the pavement with the natural environment were designed and distributed across the five south eastern states of Nigeria. These questionnaires were distributed to the general public and to persons possessing the required technical background for road construction. Findings which are in agreement with an experimental case study of one road network which connects four out of the five states under the area of study has shown that the average estimate of pavement durability lies in the range of 1 to 5 years, the ranking of durability which is a function of knowledge of worldwide trends of pavement durability lay between poor durability and average durability while factors like lack of drainage/inadequate drainage, corruption and or deliberate use of poor quality materials, inadequate thickness of pavement surfacing, improper mix design, lack of routine maintenance, and lack of periodic maintenance were among the key factors. Finally Chi-square tests showed that there were significant association between the estimate of durability and factors such as corruption and or deliberate use of poor quality materials and poor workmanship or construction as obtained from the response of the general public, while in the case of respondents with technical background, it is observed that there is a significant interaction between the estimate of durability and the poor design and construction factors and between the estimate of durability and maintenance related factors. The asymptotic significance (2-sided) ranged from 0.001 to 0.044 .
\end{abstract}

Keywords: durability estimate and ranking, flexible pavements, south-eastern Nigeria.

\section{INTRODUCTION}

Road networks are important lifelines for modern societies. Social prosperity and economic development are directly related to mobility and accessibility of communities to high quality road networks [1]. Nigeria as a whole has about $200,000 \mathrm{Km}$ of roads spread all over the country and they are made up of $32,000 \mathrm{Km}$ roads provided by federal roads the federal government, $30,000 \mathrm{Km}$ of roads provided by the state governments and over $130,000 \mathrm{Km}$ of local government roads. These provisions make Nigeria to have the largest network of roads in West Africa. In all, about 39,500 Km of the roads are paved and a good percentage of them are in very bad condition [2]. The roads which represent the major areas of investment in transportation and are the most dominant travel mode which accounts for over $90 \%$ of passenger and goods transport in Nigeria [3] should be given sufficient attention.

\section{BACKGROUND OF STUDY}

South-eastern (SE) Nigeria is not exempted from the problem of bad roads as is the case in other parts of the country. In fact the case of the south east could be described as very worse when focusing on the federal government provided roads. The south-east region is comprised of five states namely: Abia, Anambra, Ebonyi, Enugu and Imo whose population according to the 2006 census is 16,381,729 [4] with a land area of $28,982.67 \mathrm{sqKm}$ [5].The paved roads in this region are all made of flexible pavements. The geological description of south-eastern Nigeria is as shown in 
Figure. 1. It comprises of Ajali formation which is of the Maestrichtian geologic era and is close to the Nsukka formation [6]. The Nsukka formation consists of proto-Niger delta which advanced rapidly southward in the Anambra basin while the Afikpo syncline is made up of formations which ranges from the Maestrichtian to probably lower Palaeocene age [6].The Mamu formation which contains an assemblage of shale, mudstone and sandstones are fine to medium grained, typically white in colour though sometimes iron stained overlies the Enugu and Nkporo shale [7]. The Imo formation consists of a thick clayey shale which is fine textured and dark to bluish grey. It sometimes contains an admixture of clay and stone with a thin band of carbonized plant remains but becomes more sandy towards its top where it consist of bands of sandstone and shale [7]. Other formations include Odukpani formation, Ezeaku shale, Awgu shale, Ameki formation and the Ogwashi-Asabaformation [7].

The natures of flexible pavements are such that they are composed of many materials which include the subgrade, base course, subbase and the surface course. The nature or conditions of these components determine the strength and durability of the pavement. The subgrade (whether adequate, expansive, frost susceptible, pumping in nature or of highly fluctuating water table) is meant to provide a platform for the construction of the pavement. The subbase whether natural or stabilized with Portland cement, asphalt, lime, flyash, etc., is meant to support the base course, prevent the intrusion of fine grained subgrade soil into the base course and provide the drainage of free water. The base course which should be made up of good quality aggregates (bound or unbound) provides a significant portion of the structural capacity of the pavement while the surface course typically made of asphaltic concrete (wearing course, binder course etc) resist skidding, traffic abrasion and disintegration effect of climate [8]. It is therefore obvious that the conditions of these materials in terms of strength, moisture content, drainage and spatial variability affect the durability of the pavement.

The Durability of a flexible pavement is a measure of its resistance to weathering and the abrasive action of traffic within its design life. Depending on the parameter of interest, it can be measured using the thin-film oven test, rolling thin-film oven test, pressure ageing vessel method, the concept of durability index from the Marshal test or any other suitable method. With respect to asphalt paving materials, durability can also be defined as the ability of the materials in the asphalt pavement structure to withstand the effects of environmental conditions such as water, ageing and temperature variations for an extended period without any significant deterioration while considering a given amount of traffic loading [9]. Thus, the measure of how asphalt binder physical properties change with age (age hardening) is also a measure of pavement durability. Age hardening is attributed [10] to reactions such as oxidation, volatilization, polymerization, thixotropy, syneresis and separation. According to Pavement interactive [10], oxidation, a reaction of oxygen with asphalt binder, increases the viscosity of the binder making it more stiff and brittle while volatilization results in the evaporation of lighter constituents of the binder. Polymerization is the combination of like molecules to form larger molecules and it is believed to cause progressive hardening. Thixotropy which is a reversible reaction is thought to result from hydrophilic suspended particles that form a lattice structure throughout the asphalt binder while syneresis which is a form of bleeding hardens the asphalt.

The failure of pavements both structural and functional [11] in south eastern Nigeria is therefore as a result of the interplay of various factors. A case study (summarised in table 1) of Enugu-Port Harcourt dual carriage expressway which passes through four SE states: Enugu, Ebonyi, Imo and Abia by Osadebe et al. [12] portray these factors. From table 1, one can understand the variability of the wearing and binder courses, inadequacy of voids content, aggregate grading and subbase course. Considering the wearing course, it is seen that $62 \%$ and $64 \%$ of the tested samples did not meet the voids content specification for both sides of the carriage way. $20 \%$ of the samples did not meet the bitumen content specification and similar cases are observed for Marshal Flow and aggregate grading. At the binder course level, it is seen that $60 \%$ and $100 \%$ of the tested samples did not meet the requirements for aggregate grading while $60 \%$ and $17 \%$ did not meet the requirements for bitumen content for the Port-Harcourt bound and Enugu bound lanes respectively. These as reasoned will invariably shorten the life span of the pavement. 


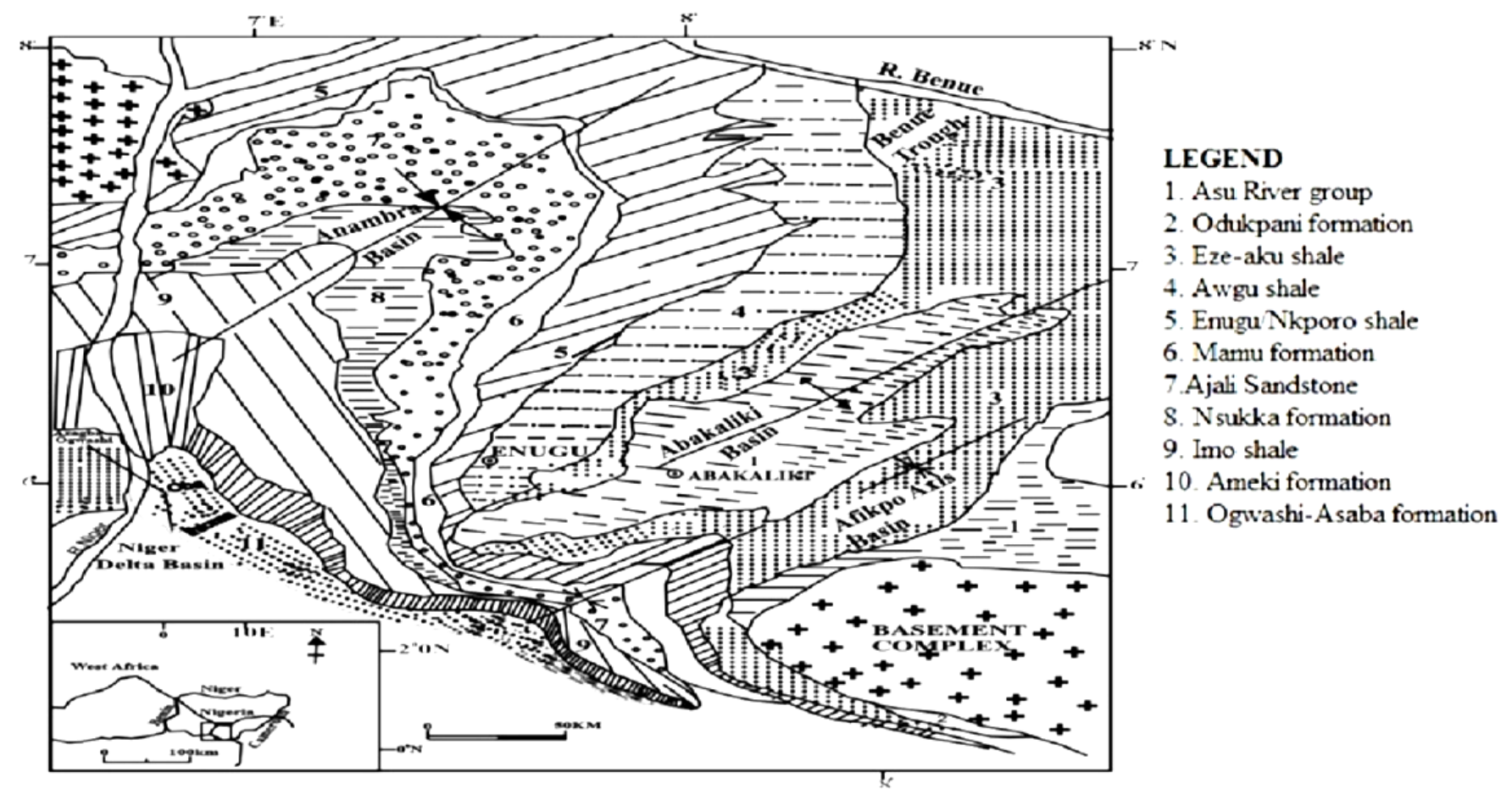

Figure1: Generalised geological map of south-eastern Nigeria

Table 1: Summary of In-situ test results on Enugu-Port Harcourt express way

\begin{tabular}{|c|c|c|c|}
\hline \multicolumn{2}{|c|}{ Parameters } & \multicolumn{2}{|c|}{ Direction } \\
\hline & & Port Harcourt Bound & Enugu Bound \\
\hline \multirow{7}{*}{ Wearing course } & $\begin{array}{l}\text { Wearing Course } \\
\text { thickness }\end{array}$ & $46-90 \mathrm{~mm}$ & $20-97 \mathrm{~mm}$ \\
\hline & & \multicolumn{2}{|c|}{ Percentage of samples not meeting basic requirements } \\
\hline & Voids content & 62 & 64 \\
\hline & Bitumen content & 20 & 0 \\
\hline & Marshal stability & 0 & 0 \\
\hline & Marshal flow & 15 & 45 \\
\hline & Aggregate grading & 70 & 37 \\
\hline \multirow{7}{*}{ Binder Course } & $\begin{array}{l}\text { Binder course } \\
\text { thickness }\end{array}$ & $53-90 \mathrm{~mm}$ & $48-98 \mathrm{~mm}$ \\
\hline & & \multicolumn{2}{|c|}{ Percentage of samples not meeting basic requirements } \\
\hline & Voids content & 0 & 10 \\
\hline & Bitumen content & 60 & 17 \\
\hline & Marshal stability & 0 & 0 \\
\hline & Marshal flow & 0 & 0 \\
\hline & Aggregate grading & 60 & 100 \\
\hline \multirow{4}{*}{ Subbase course } & $\%$ Fines & \multicolumn{2}{|c|}{48} \\
\hline & Liquid limit & \multicolumn{2}{|c|}{68} \\
\hline & Plasticity index & \multicolumn{2}{|c|}{56} \\
\hline & CBR\%(soaked) & \multicolumn{2}{|c|}{71.17} \\
\hline \multirow[t]{2}{*}{ Subgrade Layer } & \%Fines & \multicolumn{2}{|c|}{52.2} \\
\hline & CBR\%(soaked) & \multicolumn{2}{|c|}{52.74} \\
\hline Axle load survey & \multicolumn{3}{|c|}{ Equivalent load factor $=2.84$ which implies $\approx 3 \times 80 \mathrm{KN}$ standard axle } \\
\hline
\end{tabular}

Source: Osadebe et al. [12] 


\section{METHODOLOGY}

Data for the research was collected through an exploratory survey using questionnaires. An exploratory survey is a method employed in road performance modelling and is chosen in this study in order to scientifically evaluate the road user assessment of road infrastructure in the SE and also the level of agreement that this study has with the insitu study. In this regard, two distinct sets of questionnaires were distributed across the five SE states. The first category numbering four hundred and fifty (450) were distributed to people who were neither involved in road construction nor had any technical qualification required for such, while the second category numbering two hundred (200) were given in the same manner to persons with technical background who are knowledgeable and/or involved in road construction. Out of the 450 questionnaires given to the general public, 393(87.33\%) were returned while $123(61.5 \%)$ were returned by those with technical background. The high rate of return is attributed to the interest that everyone in the study area seems to have on the subject matter since it is an issue of much interest. The questionnaires for the general public sought to find out the respondents qualification, duration of stay and state of residence in the SE, their estimate of pavement durability in years and the associated durability ranking. The Question on SE state of residence is meant to ascertain whether or not the respondent resides in SE Nigeria, while the question of duration of stay in the SE was meant to help find out if the respondent actually knows the environment of interest as ordinarily the longer a person stays in an area, the better the assessment such a one can make of the environment. The question on qualification though psychological is intended to make the less qualified proves by their response that they understand the issues raised and to also encourage the more academically qualified to respond adequately. The questions for the technical respondents in addition to the ones presented above included questions on the number of years of experience in the construction industry, the type of firm and their ranking of various factors which affect flexible pavement durability. The ranking was cascaded or stepped as very low contributing, low contributing, medium contributing, high contributing and very high contributing. The question on type of firm is intended to find out whether the response of professionals in various agencies such as academic institutions, consulting firms, government regulatory firms etc would differ or whether they all will arrive at similar conclusions. The information obtained from the respondents were used to establish the generally accepted estimate of flexible pavement durability in years, predominant factors affecting pavement durability, effect of the factors on pavement durability estimate and the association between durability estimate and the various factors. In particular, Chisquare test was used as a benchmark for determining the level of significance of the research findings. The Chi-square test was chosen because it is well suited for the analysis of two of more variables that are organized either as a raw data or as frequency data. The general form of Chi-square distribution is as given in Equation (1). Finally conclusions were drawn after comparing the obtained results with that of others.

$$
x^{2}=\sum_{k=1}^{n} \frac{\left(e_{k}-f_{k}\right)^{2}}{e_{k}}
$$

Where $e_{k}$ is the expected count, $f_{k}$ is the observed count

\section{RESULTS AND DISCUSSIONS}

\subsection{General Public}

The backgrounds of the respondents from the general public are diverse and ranges from the highly educated to the just literate. The highly educated are those with qualifications up to a university degree or a postgraduate degree, while the just educated are those with not more than a primary school education. The analyses show that $1 \%$ had a PhD, MSc (4.6\%), Higher National diploma/Bachelors degree (29\%). 7.1\% had Ordinary National diploma (OND), 56.7\% had Senior School Certificate in Education (SSCE) and 1.5\% did not possess a SSCE. $51.1 \%$ of the respondents had stayed in SE Nigeria for over 15years while 49.9\%, $6.1 \%, 11.2 \%, 23.2 \%$ and $9.6 \%$ of the respondents reside in Enugu, Ebonyi, Abia, Anambra and Imo state respectively.

Considering the estimate of durability by the general public (as shown in Figure 2), 2.5\% had no idea, $24.9 \%$ said less than 2 years, $38.7 \%$ had an estimate of 3 to 5 years, $15.8 \%$ chose 6 to $8 y e a r s, 8.4 \%$ chose 9 to 11years, $9.4 \%$ chose greater than 11years and $0.3 \%$ chose other estimates. The ranking of durability had $4.6 \%$ of the respondents chose no idea, $8.7 \%$ chose not durable, $37.2 \%$ chose poor durability, $44 \%$ chose average durability, $4.1 \%$ chose high durability and $1.5 \%$ chose very high durability. Out of the $38.7 \%$ of 
respondents who believe durability to be between 3 to 5yrears, $50.7 \%$ of them ranked the roads as having average durability while $38.2 \%$ of the same group ranked the roads as having poor durability. $24.9 \%$ of the general public who estimated durability to be less than 2 years had $54.1 \%$ of them ranked the roads as having poor durability while $20.4 \%$ of the same group ranked it as average durability. Thus the authors believe that the ranking of durability seems to be a function of the knowledge of worldwide trends of pavement durability. Those who for instance know the durability estimates of 15 to 20years of roads in developed countries [13] or by their training would rank SE roads as having poor durability or very low durability considering its generally accepted life span of 1 to 5years but those without such information would rank the roads as having average durability. However this is independent of academic qualification as viewed by the authors.

Looking at the factors responsible for pavement non durability (as shown in Figure 3), 57.3\% of the respondents ranked poor quality materials as having high contributing-very high contributing effect. $49.6 \%$ of them ranked poor workmanship or construction as having high contributing-very high contributing effect. With regards to climate/weather, $75 \%$ of the respondents ranked it as very low contributionmedium contribution while $78.4 \%$ of them rated corruption and or deliberate use of poor quality materials as high contribution-very high contribution. Considering the interaction between durability estimate and the various factors responsible for pavement non durability, $80.9 \%$ of those estimating durability to be 3 to 5years believe that poor workmanship or construction has medium-high contribution effect. $61.8 \%$ of the respondents from the same group believe that lack of adequate road facilities such as drainage and shoulders has high contribution effect while $62.2 \%$ of those who opined durability estimate to be less than 2years believe it to be of high contribution-very high contribution effect. $79.6 \%$ of both respondents who estimated durability to be less than 2years and those estimating it to be 3 to 5years believe that climate/weather has very lowmedium effect on pavement durability while $81.7 \%$ and $83.6 \%$ of both respective groups believe corruption and or deliberate use of poor quality materials to be of high-very high contribution effect.

\subsection{Respondents with Technical Background}

The respondents with technical background were made up of civil engineering consultants and contractors, universities or tertiary institution instructors, site engineers, foremen, road laboratory staff, for example. The distribution of their response with respect to academic qualification is as follows: $\mathrm{PhD}$ (2.4\%),MSc (22.4\%), Higher National diploma(HND)/Bachelors degree (59.3\%), OND (6.5\%), SSCE (4.1\%), and high school and primary education (5.7\%). $31.7 \%$ of them came from a contracting firm, $12.2 \%$ (consulting firm), 33.3\% ( road supervision firms), $21.1 \%$ from educational/consulting firm and $1.6 \%$ categorised as "others". 53.7\% of the respondents had stayed in the SE for over 15years with $52.8 \%$ resident in Enugu state, 19.5\% (Ebonyi), 10.6\% Abia), 8.9\% (Anambra), and $8.1 \%$ (Imo).

Out of the 123 respondents, $50.4 \%$ estimated pavement durability to be between 3 to 5 years while $14.6 \%$ (less than 2years) thereby making $65 \%$ of the respondents among those who believe the durability of pavements to be in the range of 1 to 5years. Considering the ranking of durability, $31.7 \%$ believe the pavements to be of poor durability while $53.7 \%$ believe it to be of average durability. Out of this $53.7 \%$ of respondents, $28.79 \%, 48.48 \%$ and $1.52 \%$ estimated durability to be 6 to 8years, 3 to 5years and less than 2 years respectively while out of the $31.7 \%$ group believing pavements to be of poor durability, $58.97 \%$ and $33.33 \%$ believe the estimate of durability to be 3 to 5years and less than 2years respectively. Thus majority of the respondents irrespective of durability ranking estimated SE pavement durability to be within 3 to 5 years. Relating the estimate of durability to academic qualification, it is seen that out of the $59.3 \%$ of respondents with HND/B.SC; $16.77 \%$, $47.95 \%$ and $12.33 \%$ estimated durability to be 6 to 8years, 3 to 5 years and less than 2years respectively. Out of the $22 \%$ with MSc, $59.26 \%$ and $29.63 \%$ estimated durability to be 3-5years and less than 2years respectively while out of the $2.4 \%$ having $\mathrm{PhD}$, $66.67 \%$ and $33.33 \%$ estimated it to also be 3 to $5 y$ years and less than 2years respectively. Thus there is a trend such that the higher the academic qualification the more the percentage of persons estimating pavement durability to be 3 to 5years and less than 2years respectively. This trend also agrees with the parameter "years of experience in the construction industry" as irrespective of the number years of experience, majority agreed on the same 3-5years estimate of durability. 
Looking at the factors causing pavement non durability as shown in Table 2,it can be understood that factors like improper/inadequate data collection, inadequate thickness of base/subbase, low thickness of pavement surfacing, low quality asphalt, improper mix design, lack of drainage/inadequate drainage, corruption and or deliberate use of poor quality materials, wrong use of roads, lack of routine maintenance and lack of periodic maintenance had $60.1 \%, 71.5 \%, 67.9 \%, 76.5 \%, 73.3 \%, 73.7 \%, 93.1 \%$, $52.0 \%, 57.4 \%$ and $71.3 \%$ of the respondents respectively ranking them as having high-very high effect on pavement durability while factors like excessive elevations, bends and lack of shoulders, poor embankment design, presence of weak/problematic soils, level of water table, presence of faults and fissures, climate and weather conditions, excess security check points/congestion on the road and unnecessary or excess carriage loads on roads had $68.1 \%, 70.5 \%, 60.0 \%, 74.8 \%, 82.5 \%, 78.5 \%$ and $78.1 \%$ of the respondents respectively ranking them as having very low-medium effect on pavement durability. The excessively high values assigned to corruption/deliberate use of poor quality materials by both group of respondents $78.4 \%$ and $93.1 \%$ is in agreement with the observations of other researchers [14 and 15]. Relating these factors with the estimate of durability, it is seen that irrespective of the estimate of durability, factors such as low thickness of pavement surfacing, low quality asphalt, lack of drainage/inadequate drainage, corruption/deliberate use of poor quality material and lack of routine maintenance are believed by the majority to have very high effect on pavement durability. Improper mix design and lack of periodic maintenance are believed by the majority to have high effect; while excessive elevations, bends and lack of shoulders, poor embankment design and presence of weak/ problematic soils are believed by the majority to have medium effect on pavement durability. In the same manner, factors such as level of water table and climate/weather condition are believed to have low effect. The presence of faults and fissures are believed to have very low-medium effect while excessive security check points or traffic congestion and excessive carriage loads on pavements are taken to have very low effect-medium effect by majority of the respondents irrespective of their individual estimates of durability.

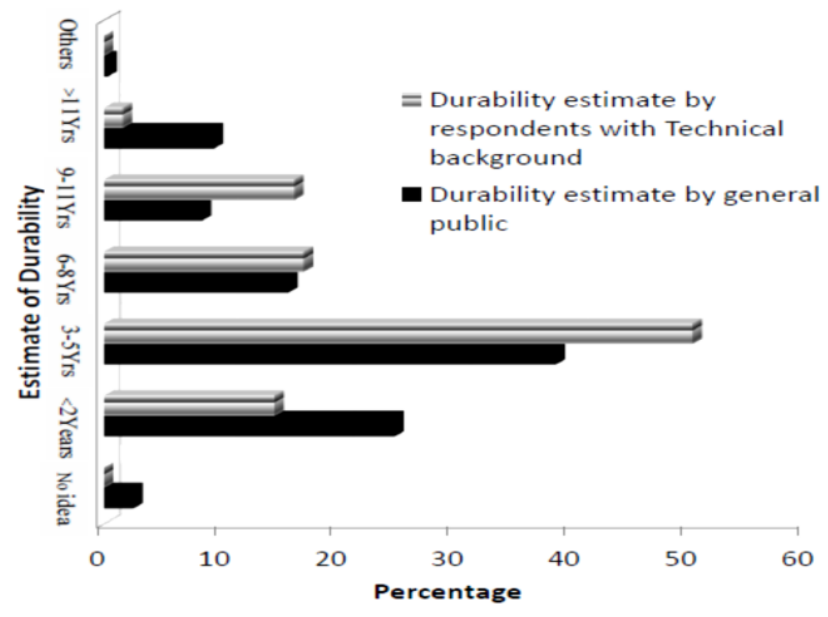

Figure 2: Estimate of durability

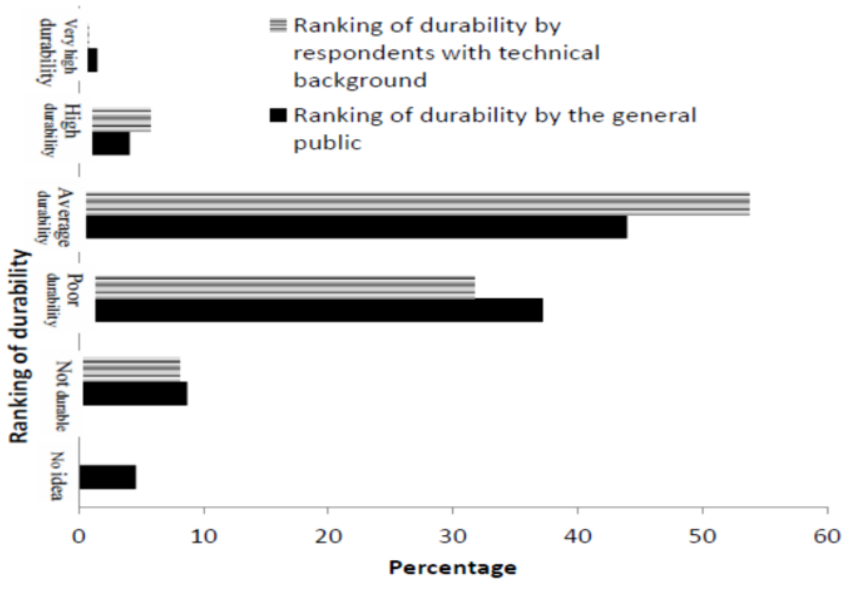

Figure 3: Ranking of Durability

Table 2: Rating of factors responsible for Pavement non durability

\begin{tabular}{lccccc}
\hline Parameters & \multicolumn{3}{c}{ Response (\%) } \\
\hline Poor Design and Construction Factors & $\begin{array}{c}\text { Very Low } \\
\text { Effect }\end{array}$ & Low Effect & $\begin{array}{c}\text { Medium } \\
\text { Effect }\end{array}$ & $\begin{array}{c}\text { High } \\
\text { Effect }\end{array}$ & $\begin{array}{c}\text { Very High } \\
\text { Effect }\end{array}$ \\
\hline $\begin{array}{l}\text { Improper/inadequate data collection } \\
\text { Excessive elevations, bends and lack of }\end{array}$ & 7.7 & 14.4 & 17.8 & 20.3 & 39.8 \\
shoulders & 12.1 & 17.2 & 38.8 & 24.1 & 7.8 \\
Inadequate thickness of Base/Subbase & 2.6 & 9.5 & 16.4 & 35.3 & 36.2 \\
Low thickness of Pavement surfacing & 1.7 & 8.7 & 21.7 & 32.2 & 35.7 \\
Low quality Asphalt & 0 & 5.2 & 18.3 & 37.4 & 39.1 \\
\hline
\end{tabular}




\begin{tabular}{|c|c|c|c|c|c|}
\hline \multirow{2}{*}{$\begin{array}{l}\text { Parameters } \\
\text { Poor Design and Construction Factors }\end{array}$} & \multicolumn{5}{|c|}{ Response (\%) } \\
\hline & $\begin{array}{l}\text { Very Low } \\
\text { Effect }\end{array}$ & Low Effect & $\begin{array}{l}\text { Medium } \\
\text { Effect }\end{array}$ & $\begin{array}{l}\text { High } \\
\text { Effect }\end{array}$ & $\begin{array}{l}\text { Very High } \\
\text { Effect }\end{array}$ \\
\hline Improper mix design & 1.7 & 4.3 & 20.7 & 44 & 29.3 \\
\hline Lack of drainage/inadequate drainage & 0.9 & 7 & 18.4 & 33.3 & 40.4 \\
\hline Poor embankment design & 12.5 & 25.9 & 32.2 & 20.5 & 8.9 \\
\hline $\begin{array}{l}\text { Corruption/Deliberate use of poor quality } \\
\text { materials }\end{array}$ & 0.9 & 3.4 & 2.6 & 22.2 & 70.9 \\
\hline \multicolumn{6}{|l|}{ Geology Related Factors } \\
\hline Presence of weak/problematic soils & 7.5 & 23.3 & 29.2 & 19.2 & 20.8 \\
\hline Level of Water table & 15.1 & 32.8 & 26.9 & 11.8 & 13.4 \\
\hline Presence of faults and fissures & 27.5 & 22.5 & 32.5 & 13.3 & 4.2 \\
\hline Climate and weather conditions & 26.4 & 33.9 & 18.2 & 12.4 & 9.1 \\
\hline \multicolumn{6}{|l|}{ Road Use Factors } \\
\hline Wrong use of Roads & 8.1 & 17.1 & 22.8 & 25.2 & 26.8 \\
\hline $\begin{array}{l}\text { Excess check points/congestion and } \\
\text { unnecessary loads on pavements }\end{array}$ & 22.8 & 28.5 & 26.8 & 14.6 & 7.3 \\
\hline \multicolumn{6}{|l|}{ Maintenance Related Factors } \\
\hline Lack of routine maintenance & 6.1 & 13 & 23.5 & 22.6 & 34.8 \\
\hline Lack of Periodic maintenance & 0.9 & 8.7 & 19.1 & 41.7 & 29.6 \\
\hline $\begin{array}{l}\text { Lack of models generating required time for } \\
\text { maintenance }\end{array}$ & 15.7 & 19.1 & 26.1 & 14.8 & 24.3 \\
\hline
\end{tabular}

Table 3: Chi square test for association between factors

\begin{tabular}{|c|c|c|c|c|}
\hline $\mathrm{S} / \mathrm{N}$ & Parameter & $\begin{array}{l}\text { Chi-squared } \\
\text { value }\end{array}$ & $\begin{array}{l}\text { Degree of } \\
\text { freedom }\end{array}$ & $\begin{array}{c}\text { Assymp. } \\
\text { Significance(2-sided) }\end{array}$ \\
\hline & Respondents with technical background & & & \\
\hline 1 & $\begin{array}{l}\text { Estimate of durability*PDC(Inadequate thickness of } \\
\text { base/subbase) }\end{array}$ & 33.399 & 16 & 0.007 \\
\hline 2 & $\begin{array}{l}\text { Estimate of Durability*PDC(Lack of } \\
\text { drainage/inadequate drainage) }\end{array}$ & 30.70 & 16 & 0.015 \\
\hline 3 & $\begin{array}{l}\text { Estimate of Durability*MRF(Lack of routine } \\
\text { maintenance) }\end{array}$ & 26.756 & 16 & 0.044 \\
\hline 4 & $\begin{array}{l}\text { Ranking of durability*MRF(Lack of routine } \\
\text { maintenance) }\end{array}$ & 31.0 & 16 & 0.013 \\
\hline & Response from the general public & & & \\
\hline 1 & $\begin{array}{l}\text { Estimate of durability*corruption/deliberate use of } \\
\text { poor quality materials }\end{array}$ & 47.303 & 30 & 0.023 \\
\hline 2 & Estimate of durability*Climate/weather & 45.471 & 30 & 0.035 \\
\hline 3 & $\begin{array}{l}\text { Estimate of durability*Poor } \\
\text { workmanship/construction }\end{array}$ & 60.469 & 30 & 0.001 \\
\hline 4 & Estimate of durability*Poor quality materials & 51.190 & 30 & 0.009 \\
\hline
\end{tabular}

\subsection{Association between factors}

The checks for association between factors were done by cross tabulation while the estimation of statistical significance was done using Chi-square tests as shown in Table 3. The cross tabulations were between the estimate of durability and the various factors affecting pavement durability which are functions of the responses obtained from the respondents. The interaction between estimate of durability and factors such as corruption and or deliberate use of poor quality materials, climate/weather, poor workmanship and the use of poor quality materials as obtained from the response of the general public were significant (did not occur by chance) and thus it is noted that there is significant association between durability estimates and the respective factors. Considering the respondents 
with technical background, it is observed that there exist a significant association between the estimate of durability and the poor design and construction factors (such as, inadequate thickness of base/subbase, lack of drainage/inadequate drainage) and between the estimate of durability and maintenance related factors (such as, lack of routine maintenance). The issue of poor/inadequate drainage has also highlighted [16].It is worthy of note that the factor "corruption/deliberate use of poor quality materials" had no significant association with the estimates of durability, although this factor was highly recommended by the respondents with technical background as a contributing factor affecting pavement durability. This could be attributed to a bias in the estimates of durability by the respondents with technical background as their estimates of durability (in years) were much higher than that from the general public as seen in Figure 2; and more so, they are the ones directly involved in the construction and design process of some of these roads in the research area.

\section{CONCLUSION}

The following conclusions are therefore drawn from this study:

i. Flexible road pavements in SE Nigeria are not durable as their estimate of durability ranges from 1to 5years.

ii. The cause of flexible pavement non-durability does not stem from the lack of skilled workers or equipments but in factors such as corruption and or deliberate use of poor quality materials.

iii. Factors such as inadequate thickness of pavement materials, low quality asphalt, lack of drainage/inadequate drainage, corruption and or deliberate use of poor quality materials and lack of routine maintenance are believed to have very high effect on pavement durability. In fact $78.4 \%$ and $93.1 \%$ of both groups of respondents point to corruption and or deliberate use of poor quality materials as an important factor.

iv. The factors having high to very high effect are in strong agreement with the communiqué of the Nigerian Building and Road Research Institute (NBRRI) [17] which described poor design and construction, use of sub-standard materials, inadequate drainage and poor periodic maintenance as factors responsible for pavement non-durability. The exception to this is traffic overloading due to inadequate axle load survey for which the respondents believe to have very low-medium effect. The above findings also agree with [18] who reported that lack of drainage maintenance was the principal reason why the Onitsha-Enugu expressway failed.

v. The parameters that have significant association with the estimates of durability whether from the general public opinion or from the opinion of respondents with technical background and those ranked as having high-very high effect should be looked into by any government willing to provide sustainable development; they are factors that negatively affect pavement durability in South Eastern Nigeria.

\section{REFERENCES}

[1] Karlaftis M and Kepaptsoglou K."Performance Measurement in the Road Sector: A cross-country review of experience". International Transport forum: Discussion Paper No. 2012-10, 2012, pp.2526.

[2] Okigbo N. "Causes of Highway Failures in Nigeria". International Journal of Engineering Science and Technology; Vol. 4, No 11, 2012, pp. 4695-4703.

[3] Oguara T. M. "A management model for road infrastructure maintenance". In: proceedings of 19th Engineering Assembly, Council for the Regulation of Engineering in Nigeria, Abuja, 3-4th August 2010.

[4] The 2006 Nigeria Census Figures. Available from: http://nigeriaworld.com/articles/2007/jan/112.ht $\underline{\mathrm{ml}}$ [accessed November 2013].

[5] The population and size of the 36 states of Nigeria. Available from:

http://www.geohive.com/cntry/nigeria.aspx [accessed November 2013]

[6] Kogbe, C. A. Geology of Nigeria, 2 ${ }^{\text {nd }}$ Ed. Rock View limited Zaramaganda, Jos, Nigeria, 1989.

[7] Okereke C N, Onu N N, Akaolisa, C Z, Ikoro D O, Ibeneme S I , Ubechu B, Chinemelu E S, and Amadikwa L O."Mapping Gully Erosion Using Remote Sensing Technique: A Case Study of Okigwe Area, Southeastern Nigeria". International Journal of Engineering Research and Applications Vol. 2, Issue 3, 2012, pp. 1955-1967.

[8] Christopher B R, Schwartz C, Boudreau R. "Geotechnical Aspects of Pavements". Reference Manual for NHI Course No. 132040, U.S. Department of Transportation, Federal Highway Administration, Washington, D.C., FHWA-NHI-05037, 2006, $888 \mathrm{p}$.

[9] Scholz T. V. and Brown S.F. "Factors affecting the durability of Bituminous Paving Mixtures", Proceedings of University Of Leeds Symposium, March 1994 in eds. Cabrera and J.R Dixon, 1996. 
[10] Pavement Interactive. Asphalt Durability. Available from:

http://www.pavementinteractive.org/article/dura bility/ [accessed March 2014]

[11] Yoder E. J. and Witczak M. W. Principles of Pavement Design, New York: Wiley, 1975.

[12] Osadebe C. C, Fakeye A M, Matawal D. S and Aitsebaomo F. O. "Road Pavement Failure in Nigeria: A case study of Enugu-Port Harcourt Expressway". In: Proceedings of National Conference on Road Pavement Failure in Nigeria, 7th -9th May 2013.

[13] Fwa T. F and Wei L. Design of Rigid Pavements: The Handbook of Highway Engineering, Ed. T. W. Fwa. CRC Press, 2005.

[14] Arowolo, D. The State, Bureaucracy and Corruption in Nigeria. In eds. Akinnowo E. O. et al. SocioEconomic Policies and Millenium Development Goals. Akure: Universal Publishers Inc, 2008.
[15] Ayodele E, Olusegun O, Akintoye B, Ariyo, I and Alabi O. "Corruption in the Construction Industry of Nigeria: Causes and Solutions". Journal of Emerging Trends in Economics and Management Sciences Vol. 2 (3), 2011, pp. 156-159

[16] Agbonkhese O, Yisa G L, Daudu P. I. "Bad Drainage and Its Effects on Road Pavement Conditions in Nigeria". Civil and Environmental Research Vol. 3 (10), 2013, pp. 7-15.

[17] Communiqué of the Technical Workshop on Road Pavement Failure Organised by the Nigerian Building and Road Research Institute (NBRRI), Available from: nbrri.gov.ng/docs/NBRRI\%20RoadConf2013_Com munique.pdf [accessed November 2013].

[18] Chidolue C. A, Nwajaku, A. I, Okonkwo, V. O. "Rehabilitation of Onitsha-Enugu Dual Carriageway in Anambra State, Nigeria: Lessons Learned". Nigerian Journal of Technology Vol. 32, No. 3, 2013, pp. 393-402. 